childhood accidents. West Germany too has a similar organisation and has found it equally effective.

A committee related to accidents in childhood is needed because (a) the kinds of accidents and where they happen are different in children and adults; (b) more of these accidents affect young children, and the circumstances need different modes of prevention; (c) no organisation exists to prevent accidents in children; and $(d)$ the economic cost and loss to the nation is much greater when permanent damage occurs in childhood. The committees that already exist to co-ordinate the efforts of government departments and other public and voluntary bodies in this field are concerned almost exclusively with adults. The problem of childhood accidents cannot be tackled by applying to a younger age group the means of prevention that are successful in adults.

Although we believe that such an organisation would be valuable, we are, nevertheless, realistic about what can be done in the long run. In discussing the work of the Swedish committee, a recent booklet ${ }^{15}$ concludes with the following statement:

"It may sound paradoxical, but we do not expect, and do not even aim at, a national reduction in the total number of accidents. The vast majority of childhood accidents result in minor injuries. They are to a large extent unavoidable and even desirable from the educational point of view. We do not want to restrict the child's normal and free development and behaviour by trying to shield him from many types of accidents. What we are striving for is to prevent serious types of accidents and potential causes of disability or death. Even a very good result within this limited scope would only slightly reduce the total number of accidents; but it would bring about a further reduction of childhood mortality and disability, and this is what we are hoping for." This seems to be a practical and sensible approach and one which we support. We believe that the formation of a joint committee on childhood accident prevention would be an important step in this direction.

\section{References}

1 BPA and BAPS Joint Accident Committee, Survey of Attendances at Accident and Emergency Departments. Unpublished, (see Archives of Disease in Childhood, 1972, 47, 317.)

2 Illingworth, C, Attendances at the Accident and Emergency Department, Children's Hospital, Sheffield. 1972, unpublished.

${ }^{3}$ Lade, R M, et al, Slaughter House, report No 112. London, Health Education Council, Medical Research Division, 1974.

${ }^{4}$ de Fonseka, C P, et al, Studies of Home Accidents: Injury to Children in Home Accidents, report No 86. London, Health Education Council, Research Division, 1974.

${ }^{5}$ Sandels, S, Children in Traffic. Paul Elek, London, 1975.

${ }^{6}$ Howarth, C I, Routledge, D A, and Repetto-Wright, R, Ergonomics, $1974,3,319$.

${ }^{7}$ Accidents in Childhood as a Public Health Problem. Strasbourg, Council of Europe, 1972.

${ }^{8}$ Department of Prices and Consumer Affairs, Fireworks: $A$ Consultative Document. London, HMSO, 1975.

${ }^{9}$ Craft, A W, Shaw, D A, and Cartlidge, N E F, British Medical fournal, $1973,4,146$.

${ }^{10}$ Ministry of Health and Scottish Home and Health Department, Hospital Treatment for Acute Poisoning. London, HMSO, 1968.

11 British Medical fournal, 1975, 4, 483.

${ }^{12}$ British Medical fournal, 1968, 3, suppl, p 67.

${ }^{13}$ Medical Aspects of Fitness to Drive, 2nd edn. London, Medical Commission on Accident Prevention, 1971.

${ }^{14}$ Medical Aspects of Home Hazards. London, Medical Commission on Accident Prevention, 1972.

15 Ehrenpreis, T, Prevention of Childhood Accidents in Sweden. Stockholm, Swedish Institute, 1973.

${ }^{16}$ Registrar General's Statistical Review of England and Wales for the year 1973, part I (B), Tables, Medical. London, HMSO, 1976.

\title{
Statistics at Square One
}

\section{I-Tabulation of data}

\section{T D V SWINSCOW}

British Medical fournal, 1976, 1, 1262-1263

\section{Introduction}

Many observations made in medicine are most naturally expressed in words. For instance, we might say, "His pulse could not be recorded." But for many others the most natural mode of expression is in numbers, as in the phrase, "His pulse was beating at 80 per minute." The purpose of statistical methods is to put numerical data into a context by which their meaning can be better judged. The intention of this and succeeding articles is to show how some useful statistical methods can be used. No mathematical knowledge beyond simple arithmetic is required.

Some knowledge of statistical methods is advantageous-even essential-for two reasons. Firstly, just as discussing his data in words often helps an investigator to understand them better, so testing the numerical results statistically, by his own effort,

British Medical Journal

T D V SWINSCOW, MSC, MB, deputy editor gives him a clearer view of their significance. Secondly, statisticians themselves are busy if helpful people, and are not always available to solve the sort of simple problems that will be discussed in these articles.

The small, moderately priced electronic calculators now generally available have made the computation of elementary statistics a simple matter. The methods to be described here will therefore be adapted to their use. Suitable instruments have keys for squares, square roots, change of sign, and a memory in addition to the usual arithmetical keys. Though simpler calculators can be of help, keys of squares and square roots save much labour, while a memory obviates the need to record intermediate stages of some calculations on paper. More complex desk calculators with special statistical functions exist, but they are unnecessary for the calculations to be discussed here. One of the great advantages of the electronic over the older mechanical calculators is that they provide instant squares, square roots, and reciprocals at the push of a button.

\section{Tabulation}

Before any statistical calculation, even of the simplest kind, is performed on data they are tabulated. If they are relatively 
few, say up to about 30 , they are conveniently written down in order of size.

For example, Dr Green, a paediatric registrar in a district general hospital, is investigating the amount of lead in the urine of children from a nearby housing estate. In a particular street there are 15 children whose ages range from 1 year to under 16 , and in a preliminary study he has found the following amounts of urinary lead (in $\mu \mathrm{mol} / 24 \mathrm{~h}$ ), taken from his notes in random order and then set down thus in what is sometimes ealled an array:

TABLE 1.1-Urinary concentration of lead in 15 children, $\mu$ mol/24

$0 \cdot 1.0 \cdot 4,0 \cdot 6,0 \cdot 8,1 \cdot 1,1 \cdot 2,1 \cdot 3,1 \cdot 5,1 \cdot 7,1 \cdot 9,1 \cdot 9,2 \cdot 0,2 \cdot 2,2 \cdot 6,3 \cdot 2$

The advantage of first setting the figures out in order of size and not simply feeding them straight from the notes into a calculator (for example, to find their mean) is that the relation of each to the next can be looked at. Is there a steady progression, a noteworthy hump, a considerable gap ? Simple inspection can disclose irregularities. Furthermore, a glance at the figures gives information on their range. The smallest is $0 \cdot 1$ and the largest 3.2. To find their mean (or average) Dr Green adds them up, getting a total of 22.5 , and divides this by the number of observations, 15 , to get $1.5 \mu \mathrm{mol} / 24 \mathrm{~h}$.

\section{Frequency distribution}

But the results from only 15 children are too few for Dr Green's purpose, so he extends his inquiry to the whole of the small industrial estate in which the street lies. In consequence he obtains figures for the urinary lead concentration in 140 children aged over 1 year and under 16 . To make them manageable these figures are best tabulated in a frequency distribution. This is simply a classification of numbers of children by the concentration of lead in their urine, so that against successive amounts of lead the corresponding number of children will be recorded.

To make this classification Dr Green must decide on suitable class intervals for the lead concentrations in his frequency distribution. If the classes are too small the table will be unwieldy; if they are too large, information will be lost by being too summary. The divisions chosen must also be such that the actual data can easily be allotted to them, and they must be mutually exclusive.

The range of readings for the 140 children was 0.1 to $4.2 \mu \mathrm{mol} /$ $24 \mathrm{~h}$. If the classes are set at intervals of $0.5 \mu \mathrm{mol} / 24 \mathrm{~h}$, nine will be needed to cover this range; if at $0.4,11$; if at $0.25,18$; and if at $0 \cdot 2,22$. Between about 10 and 20 classes are generally acceptable in practice. It is also helpful to fix the class intervals so that the half-way points between them are instantly evident on inspection, because they will be needed for calculation of the mean and standard deviation. Thus half way between 1.8 and 2.0 is clearly 1.9 , but half way between 1.75 and 2.0 is not so immediately obvious (1.875). Finally, classes are better initially chosen to be too small than too large, because small ones can easily be amalgamated later to form large ones if necessary. Weighing up these somewhat conflicting considerations, Dr Green decided to start with class intervals of $0 \cdot 2$, providing 22 classes.

The tabulation of the data from notes is done as shown in fig 1.1, a stroke being placed for each value of lead concentration against its class interval. When four strokes have accumulated they are scored through with a fifth to facilitate counting in groups of five. Because the intervals of $0.2 \mu \mathrm{mol} / 24 \mathrm{~h}$ used in this first tabulation led to rather a large table Dr Green decided to compile a second table from it with class intervals of double the size-namely, $0.4 \mu \mathrm{mol} / 24 \mathrm{~h}$. He felt free to do this because, firstly, the distribution of patients progresses fairly steadily from class to class, so that amalgamation will not obscure real discontinuities between classes; and, secondly, because the figures

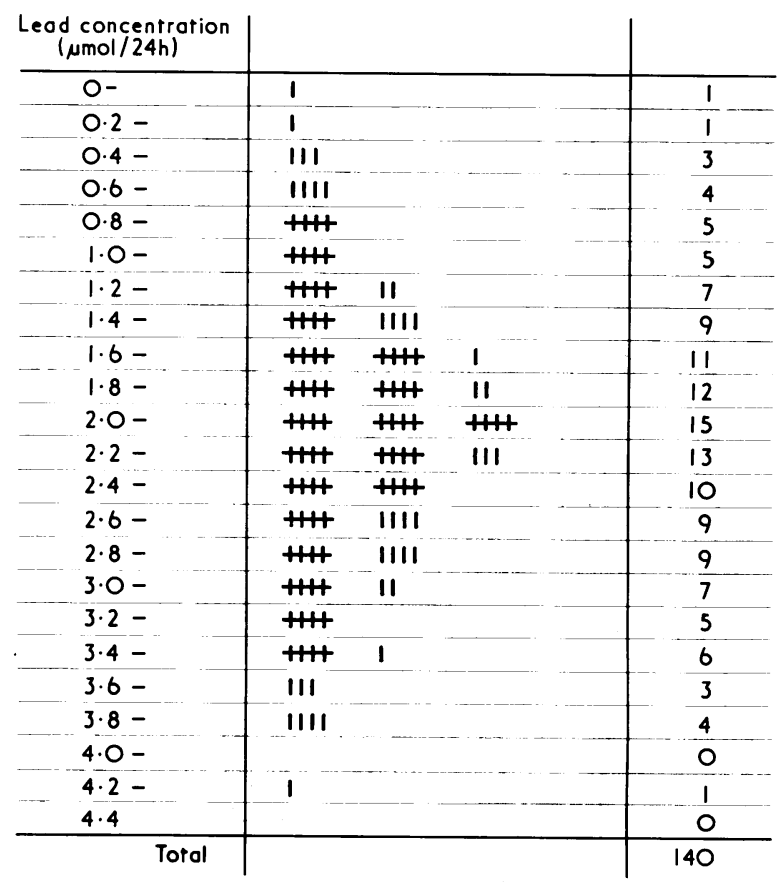

FIG 1.1-Tabulation of data to construct a frequency distribution.

themselves are not so precise as they may appear to be, for they are subject to errors of physiological variation, clinical sampling, and laboratory measurement. The result of amalgamating the $0.2 \mu \mathrm{mol}$ classes to form $0.4 \mu \mathrm{mol}$ classes is shown in table 1.2. It includes the total number of children. But is it correct to base calculations on this total group of 140 ? Some problems there will be discussed next week.

TABLE 1.2-Lead concentration in urine of children

\begin{tabular}{c|c}
\hline Lead concentration $(\mu \mathrm{mol} / 24 \mathrm{~h})$ & Number of children \\
\hline $0.4-$ & 2 \\
$0 \cdot 4-$ & 7 \\
$0.8-$ & 10 \\
$1 \cdot 2-$ & 16 \\
$1.6-$ & 23 \\
$2 \cdot 0-$ & 28 \\
$2 \cdot 4-$ & 19 \\
$2 \cdot 8-$ & 16 \\
$3 \cdot 2-$ & 7 \\
$3 \cdot 6-$ & 1 \\
$4 \cdot 0-$ & \\
\hline $4 \cdot 4$ & 140
\end{tabular}

Exercise 1. In another group of children Dr Green found the following urinary lead concentrations (in $\mu \mathrm{mol} / 24 \mathrm{~h}$ ): $0.02,0.24,1.72,2.98$, $1.32,0.95,1.44,3.12,1.15,0.87,1.21,2.02,0.91,2.03,0.31,0.52$. What is the mean? Answer: $1 \cdot 30$.

In the preparation of this and succeeding articles of the series I received invaluable advice from Professor P Armitage, for which I am most grateful. The faults that remain are certainly mine.

When applying for a provisional driving licence should a 17-year-old mention a grand mal convulsion which occurred three to four days after an appendicectomy five years ago? He has had no more fits.

Anyone who had a fit many years ago need not mention this when he applies for a licence; he in no way should be considered to suffer from epilepsy. A patient who has epilepsy may have a driving licence if he has been free from any epileptic attacks, while awake, for three years. The fact that he is still on anticonvulsant medication does not prevent him from having a driving licence. 